\title{
Additive antitumour effect of the epidermal growth factor receptor tyrosine kinase inhibitor gefitinib (Iressa, ZDI839) and the antioestrogen fulvestrant (Faslodex, ICl I82,780) in breast
} cancer cells

\author{
S Okubo', J Kurebayashi*,', T Otsuki', Y Yamamoto', K Tanaka' and H Sonoo' \\ 'Department of Breast and Thyroid Surgery, Kawasaki Medical School, 577 Matsushima, Kurashiki, Okayama 701-0192, Japan; '2Department of \\ Hygiene, Kawasaki Medical School, 577 Matsushima, Kurashiki, Okayama 701-0192, Japan
}

\begin{abstract}
A high expression level of epidermal growth factor receptor (EGFR)/HERI has been suggested to lead to a shorter survival time and resistance to endocrine therapy in patients with breast cancer. To test the hypothesis that inhibition of the EGFR signalling pathway affects the antitumour effect of endocrine therapy, an EGFR tyrosine kinase inhibitor (EGFR-TKI), gefitinib, and an oestrogen receptor (ER) antagonist, fulvestrant, were administered to human breast cancer cells. A total of five human breast cancer cell lines were used. The effects of single or combined treatments with gefitinib and/or fulvestrant on cell growth, cell cycle progression and apoptosis were analysed. Changes in the expression levels of cyclin-dependent kinase inhibitors, p2I and p27, an antiapoptotic factor, Bcl-2, and a proapoptotic factor, Bax, were also investigated. All cell lines tested were sensitive to gefitinib (50\% growth inhibitory concentration, 10-28.5 $\mu \mathrm{M}$ ). Breast cancer cell lines with a high expression level of HERI or HER2 were more sensitive to gefitinib than the others. Gefitinib induced a significant GI-S blockade in ER-positive KPL-3C cells. Gefitinib induced significant apoptosis in HERIoverexpressing MDA-MB-23I cells. Gefitinib additively increased the antitumour effect of fulvestrant in all three ER-positive cell lines in a medium supplemented with $17 \beta$-oestradiol. The combined treatment promoted cell cycle retardation in KPL-3C cells, which is associated with an upregulation of $\mathrm{p} 2 \mathrm{I}$ by fulvestrant and gefitinib, respectively. Apoptosis was associated with downregulation of Bcl2 by gefitinib in MDA-MB-23I cells. These results suggest an additive interaction between the EGFR-TKI gefitinib and the antioestrogen fulvestrant in ER-positive breast cancer cells.

British Journal of Cancer (2004) 90, 236-244. doi: I0.1038/sj.bjc.660I504 www.bjcancer.com
\end{abstract}

(c) 2004 Cancer Research UK

Keywords: gefitinib; fulvestrant; breast cancer; HERI; p2I; Bcl-2

Epidermal growth factor receptor (EGFR)/HER1 is a member of the HER/erbB family of transmembrane tyrosine kinases. Binding of specific ligands, such as EGF or transforming growth factor- $\alpha$, to the extracellular domain of EGFR/HER1 results in homodimerisation or heterodimerisation with another member of the HER/erbB family, HER2/erbB2, HER3/erbB3 or HER4/erbB4. This dimerisation induces autophosphorylation of tyrosine residues of the intracellular domain of EGFR/HER1, which activates intracellular signalling cascades such as the Ras/Raf/ERK/MAPK, PI-3K/AKT and PLC $\gamma$ pathways. These interactions modulate several cellular functions such as proliferative activity and apoptosis. Under normal conditions, EGFR/HER1 signalling is tightly controlled by various physiological mechanisms (Yarden and Sliwkowski, 2001).

Aberrant EGFR/HER1 signalling, such as high expression of EGFR/HER1, is causally associated with enhanced tumour cell proliferation and shorter survival in patients with solid tumours

*Correspondence: Dr J Kurebayashi; E-mail: kure@med.kawasaki-m.ac.jp Received 27 June 2003; revised 17 October 2003; accepted 24 October 2003 such as breast cancer (Arteaga, 2002). It has been reported that EGFR/HER1 is expressed at high levels in at least $20 \%$ of breast cancers. This high expression has been suggested to correlate with a shorter survival time and resistance to endocrine therapy in patients with breast cancer (Sainsbury et al, 1987; Nicholson et al, 1989; Newby et al, 1995). In addition, a series of experimental and clinical findings have suggested that aberrant activation of tyrosine receptor kinases, such as EGFR/HER1 and HER2 pathways, play a causal role in the development of antioestrogen resistance in breast cancer (van Agthoven et al, 1992; Benz et al, 1993; Houston et al, 1999; Dowsett et al, 2001; Wakeling et al, 2001).

Gefitinib (Iressa, ZD1839) is an orally active EGFR-tyrosine kinase inhibitor (TKI) that blocks signal transduction pathways implicated in proliferation and survival of cancer cells (Baselga and Averbuch, 2000). Recent studies have suggested that gefitinib induces cell cycle retardation and apoptosis, and inhibits the growth of several types of human cancer cells expressing EGFR both in vitro and in vivo (Ciardiello et al, 2000; Sirotnak et al, 2000; Ciardiello et al, 2001; Moasser et al, 2001; Moulder et al, 2001; Bianco et al, 2002; Ciardiello et al, 2002; Fujimura et al, 2002; Huang et al, 2002; Janne et al, 2002; Magne et al, 2002; Williams 
et al, 2002). In addition, human breast cancer cells overexpressing HER2 or acquiring resistance to the oestrogen receptor (ER) antagonist, fulvestrant (Faslodex, ICI 182,780), have been reported to be particularly sensitive to gefitinib (McClelland et al, 2001; Moulder et al, 2001). Furthermore, phase I trials of gefitinib in patients with solid tumours refractory to standard chemotherapies have shown good tolerability and promising antitumour activity (Baselga et al, 2002; Herbst et al, 2002; Ranson et al, 2002). These findings suggest that gefitinib will be clinically useful in the treatment of patients with hormone-refractory breast cancer.

To test the hypothesis that inhibition of the EGFR/HER1 signalling pathway affects the antitumour effect of endocrine therapy, gefitinib and fulvestrant were administered to human breast cancer cells. We found that gefitinib increases the antiproliferative effect of fulvestrant in ER-positive breast cancer cells under $17 \beta$-oestradiol (E2)-supplemented conditions. In addition, this effect is caused by cell cycle retardation (G1-S blockade) and an increase in apoptosis. To investigate more detailed mechanisms of action of gefitinib and fulvestrant, changes in the expression levels of cyclin-dependent kinase inhibitors (CDKIs), p21 and p27, an antiapoptotic protein, Bcl-2 and a proapoptotic protein, Bax, were also investigated.

\section{MATERIALS AND METHODS}

\section{Reagents}

E2 was purchased from Sigma Chemical Co. (St Louis, MI, USA). Both fulvestrant and gefitinib were kindly provided by AstraZeneca (Macclesfield, UK). E2 and fulvestrant were dissolved with $100 \%$ ethanol and added to the medium at a final ethanol concentration of $0.2 \%$. Gefitinib was dissolved with DMSO and added to the medium at a final concentration of $0.1 \%$.

\section{Cell lines}

KPL-1, KPL-3C and KPL-4 human breast cancer cell lines were established in our laboratory (Kurebayashi et al, 1995; Kurebayashi et al, 1996; Kurebayashi et al, 1999). KPL-1 cells are derived from a postmenopausal patient with hormone-refractory breast cancer. This cell line is ER $\alpha$-positive and oestrogen responsive in vitro but not in vivo (Kurebayashi et al, 2000a). KPL-3C cells are derived from a premenopausal patient with breast cancer associated with humoral hypercalcemia. This cell line is ER $\alpha$ positive and oestrogen responsive both in vitro and in vivo. KPL-4 cells are derived from a postmenopausal patient with inflammatory skin metastasis from breast cancer. This cell line expresses a high level of HER2 associated with HER2/neu gene amplification. T47D and MDA-MB-231 cell lines were kindly provided by Dr Robert B Dickson (Lombardi Cancer Research Center, Georgetown University Medical Center, Washington DC, USA). All cell lines were routinely cultured in Dulbecco's minimal essential medium (DMEM) supplemented with $5 \%$ fetal bovine serum (FBS).

\section{Expression levels of ER, progesterone receptor (PgR) and HER family members}

The expression levels of ER and PgR in the cell pellets of the breast cancer cell lines were measured by an enzyme immunoassay using the ER-EIA and PgR-EIA kits (Dinabot Inc., Tokyo, Japan), according to the manufacturer's recommendations. The expression levels of HER family members were measured by the multiplex reverse transcription-polymerase chain reaction (RT-PCR) as described previously (Kunisue et al, 2000; Kurebayashi et al, 2000b). Oligonucleotide primers were designed using a published sequence of each target gene and synthesised by the solid-phase triester method. To amplify both the internal control gene $(\beta$ actin) and one of the target genes in a single reaction, multiplex
PCR was carried out. The relative expression levels were calculated as the density of the product of the respective target genes divided by that of the control gene. In addition, protein expression levels of HER1 and HER2 were measured by Western blotting using antiHER1 goat polyclonal antibody (Santa Cruz Biotechnology, Santa Cruz, CA, USA) and anti-HER2 mouse monoclonal antibody (Santa Cruz Biotechnology), respectively. Detailed procedure of immunoblot analysis is described below.

\section{Growth assay and cell cycle analysis}

To reduce endogenous oestrogen-like activity, phenol red-free RPMI-1640 medium (Gibco BRL, Bethesda, MD, USA) supplemented with $5 \%$ dextran-coated charcoal-stripped FBS (Hyclone, UT, USA) (oestrogen-deprived medium) was used. Approximately $2 \times 10^{5}$ cells well $^{-1}$ were inoculated into 12 -well plates (Costar Corning Inc., Corning, NY, USA) and cultured in D-MEM supplemented with 5\% FBS for 2 days. Then, the cells were washed twice with phosphate-buffered saline (PBS) and cultured for 2 days in the oestrogen-deprived medium with vehicle (control), $1 \mathrm{nM} \mathrm{E2}$, the indicated concentrations of gefitinib and/ or fulvestrant. After cell dispersion with $0.05 \%$ trypsin (Difco, Detroit, MI, USA) and $0.02 \%$ EDTA in PBS for $10 \mathrm{~min}$, the cell numbers were measured with a Coulter counter (Coulter Electronics Ltd, Harpenden, UK). Triplicate wells were treated in each experiment.

To investigate the effect of the agents on cell cycle progression, a part of the harvested cells were stained with propidium iodide using the CycleTest Plus DNA Reagent kit (Becton Dickinson, San Jose, CA, USA). Flow cytometry was performed with a FACSCaliber flow cytometer (Becton Dickinson), and the DNA histogram was analysed by a CELLQuest version 1.2.2 (Becton Dickinson) as described previously (Kunisue et al, 2000).

\section{Apoptosis assay}

Approximately $5 \times 10^{5}$ cells well $^{-1}$ were plated into T-25 flasks (Corning Japan, Tokyo, Japan) and cultured in D-MEM supplemented with 5\% FBS for 2 days. Then, the cells were washed twice with PBS and cultured for 2 or 4 days in the oestrogen-deprived medium with vehicle (control), $10 \mu \mathrm{M}$ gefitinib, $1 \mathrm{nM} \mathrm{E2,} 1 \mathrm{nM} \mathrm{E2}$ plus $100 \mathrm{~nm}$ fulvestrant, $1 \mathrm{~nm}$ E2 plus $10 \mu \mathrm{M}$ gefitinib or $1 \mathrm{nM}$ E2 plus $100 \mathrm{~nm}$ fulvestrant and $10 \mu \mathrm{m}$ gefitinib. Duplicate flasks were trypsinised and harvested. The percentages of apoptotic cells were measured with a FACSCaliber flow cytometry (Becton Dickinson) using an in situ cell death detection kit (Roche Diagnostics $\mathrm{GmbH}$, Mannheim, Germany), according to the manufacturer's recommendations as described previously (Kunisue et al, 2000).

\section{Immunoblot analysis}

Approximately $4 \times 10^{5}$ cells well $^{-1}$ were plated in six-well plates (Costar Corning Inc.) and cultured in D-MEM supplemented with $5 \%$ FBS for 2 days. Then, the cells were washed twice with PBS and cultured for 2 days in the oestrogen-deprived medium with vehicle (control), $10 \mu \mathrm{m}$ gefitinib, $1 \mathrm{nM} \mathrm{E2,} 1 \mathrm{nM}$ E2 plus $100 \mathrm{~nm}$ fulvestrant, $1 \mathrm{nM} \mathrm{E} 2$ plus $10 \mu \mathrm{M}$ gefitinib or $1 \mathrm{~nm}$ E2 plus $100 \mathrm{~nm}$ fulvestrant and $10 \mu \mathrm{M}$ gefitinib. Then, the cells were washed once with cold PBS and lysed by $200 \mu \mathrm{lwell}^{-1}$ of cold RIPA buffer ( $50 \mathrm{~mm}$ Tris-HCl (pH 7.4), $150 \mathrm{~mm} \mathrm{NaCl}, 1 \%$ Nonidet P-40, 1\% deoxycholic acid sodium, $0.05 \%$ SDS) plus $4 \mu \mathrm{l}_{\text {well }}^{-1}$ of protease inhibitor (Sigma Chemical Co.). The cell lysate was clarified by centrifugation at $14000 \mathrm{~g}$ at $4^{\circ} \mathrm{C}$ for $10 \mathrm{~min}$. In total, $20-30 \mu \mathrm{g}$ protein was heated in Laemmli gel loading buffer for $5 \mathrm{~min}$ at $95^{\circ} \mathrm{C}$ and subjected to electrophoresis on $12.5 \%$ polyacrylamide gel (Bio-Rad, Richmond, CA, USA). The protein was transferred to nitrocellulose membranes (Amersham Life Sciences, Buckinghamshire, UK) and immunoblotted with appropriate primary antibodies. For detec- 
tion, the blots were incubated with the appropriate secondary antibodies conjugated with horseradish peroxidase (Santa Cruz Biotechnology), and developed using ECL Plus Western Blotting Detection Reagents (Amersham Life Sciences), according to the instructions of the manufacturer. Both anti-p21 and anti-p-27 monoclonal antibodies were obtained from Nippon Becton Dickinson (Tokyo, Japan). Anti-Bcl-2 and anti-BAX monoclonal antibodies were obtained from Dako Japan (Tokyo, Japan) and Medical and Biological Laboratories Co. (Tokyo, Japan), respectively. Both anti-actin and anti- $\alpha$-tubulin monoclonal antibodies were obtained from Santa Cruz Biotechnology. Densinometry was performed using Image-Pro Plus Version 4.0 (Planetron, Tokyo, Japan). The intensities of the proteins were normalised to the actin or $\alpha$-tubulin band and quantified by comparing with those of control cells. Reproducibility was confirmed in at least two separate experiments.

\section{Statistical analysis}

All values are expressed as the mean \pm s.e. ANOVA analysis with StatView computer software (ATMS Co., Tokyo, Japan) was used to compare the differences between two groups. A two-sided $P$ value less than 0.05 was considered to be statistically significant.

\section{RESULTS}

\section{Expression levels of ER, PgR and HER family members}

KPL-1 and KPL-3C cells expressed a high level of ER and undetectable PgR in the oestrogen-deprived condition (but PgR is inducible by an E2 supplementation) (Kurebayashi et al, 1996; Kurebayashi et al, 2000a). T47D cells expressed a low level of ER associated with a very high level of PgR in the oestrogen-deprived condition. Both KPL-4 and MDA-MB-231 cells expressed neither ER nor PgR (Kurebayashi et al, 2000b; Table 1). In contrast, all cell lines expressed a detectable level of each HER family member by the RT - PCR. KPL- 4 cells expressed a highest level of HER2, and MDA-MB-231 expressed a highest level of HER1 (Table 1). Western blot analysis also supported these findings (Figure 1).

\section{Antitumour effect of gefitinib alone}

Gefitinib alone dose dependently inhibited the growth of all breast cancer cell lines tested (Figure 2). The mean 50\%-growth inhibitory concentrations of gefitinib were $28.5 \pm 1.5 \mu \mathrm{M}$ for KPL1 cells, $25.0 \pm 1.0 \mu \mathrm{M}$ for KPL-3C cells, $25.0 \pm 3.0 \mu \mathrm{M}$ for T47 D cells, $10.0 \pm 1.0 \mu \mathrm{M}$ for KPL- 4 cells and $10.0 \pm 0.5 \mu \mathrm{M}$ for MDA-MB-231 cells, respectively ( $n=2$ each). HER1-overexpressing MDA-MB231 and HER2-overexpressing KPL-4 cell lines were more sensitive to gefitinib than the other cell lines.

\section{Effects of E2, fulvestrant and gefitinib on cell growth}

In KPL-1, KPL-3C and T47D cells, $1 \mathrm{nM} \mathrm{E2} \mathrm{significantly} \mathrm{stimulated}$ their growth. Both $100 \mathrm{~nm}$ fulvestrant and $10 \mu \mathrm{M}$ gefitinib significantly reduced the growth-stimulatory effect of E2. Simulta-

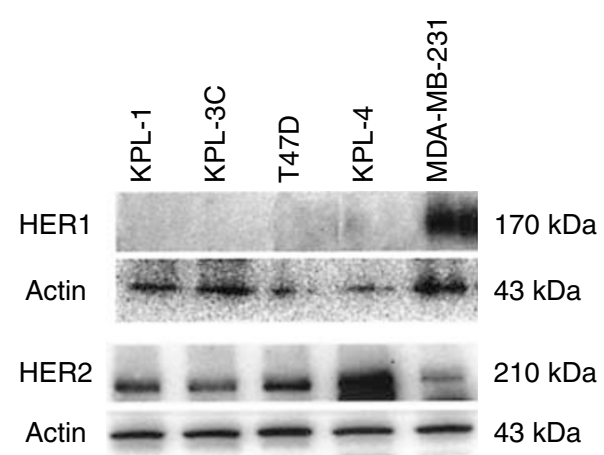

Figure I Western blot analysis on expression levels of EGFR/HERI and HER2 in five breast cancer cell lines tested. The harvested cells were lysed, and the lysate was subjected to electrophoresis on polyacrylamide gel. The protein was transferred to nitrocellulose membranes and immunoblotted with appropriate primary antibodies. For detection, the blots were incubated with the appropriate secondary antibodies conjugated with horseradish peroxidase, and developed using ECL Plus Western Blotting Detection Reagents. Actin was used as the internal control.

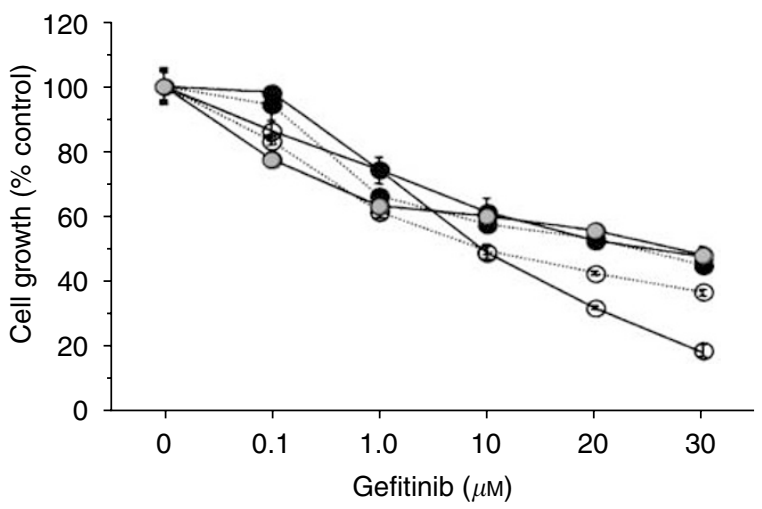

Figure 2 Effect of gefitinib alone on the cell growth of five human breast cancer cell lines tested. Semiconfluent cells were cultured for 2 days in the oestrogen-deprived medium with vehicle, 0. I, I.0, 10, 20 or $30 \mu \mathrm{M}$ gefitinib. After cell dispersion, the cell numbers were measured with a Coulter counter. Triplicate wells were treated in each experiment. Values represent means \pm s.e. $-\mathrm{KPL}-\mathrm{I}$; - - - KPL-3C; ○-O, T47D; O - - O, KPL4; and $\mathrm{O}-\mathrm{O}, \mathrm{MDA}-\mathrm{MB}-23 \mathrm{I}$.

neous addition of fulvestrant and gefitinib additively reduced the growth-stimulatory effect of E2. In either KPL-4 or MDA-MB-231 cells, gefitinib significantly inhibited the cell growth but fulvestrant did not (Figure 3). In contrast, no significant growth inhibitory effect of fulvestrant was observed in all cell lines tested, and the simultaneous addition of fulvestrant and gefitinib did not additively inhibit the growth of the ER-positive cell lines in the absence of E2 (data not shown).

Table I Expression levels of ER, PgR and HER family members in human breast cancer cell lines tested

\begin{tabular}{lccccc}
\hline Cell line & ER $^{\mathbf{a}}$ & PgR $^{\mathbf{a}}$ & HER $^{\mathbf{b}}$ & HER2 $^{\mathbf{b}}$ & HER3 $^{\mathbf{b}}$ \\
\hline KPL-1 & $79.7 \pm 13.3$ & $N D^{c}$ & 1.5 & 3.0 & HER4 $^{\mathbf{b}}$ \\
KPL-3C & $90.9 \pm 18.2$ & $N D$ & 0.8 & 3.0 & 2.5 \\
T47D & $32.5 \pm 1.0$ & $8480.0 \pm 720.0$ & 1.3 & 3.7 & 2.7 \\
KPL-4 & $N D$ & $N D$ & 1.8 & 9.5 & 2.0 \\
MDA-MB-23| & ND & ND & 3.0 & 2.6 & 1.3 \\
\hline
\end{tabular}

${ }^{a}$ Femtomoles $\mathrm{mg}^{-1}$ protein measured by EIA (mean \pm s.e.). ${ }^{b}$ Expression ratio in comparison with internal control ( $\beta$-actin) by multiplex RT-PCR. ${ }^{c}$ Not detectable. 

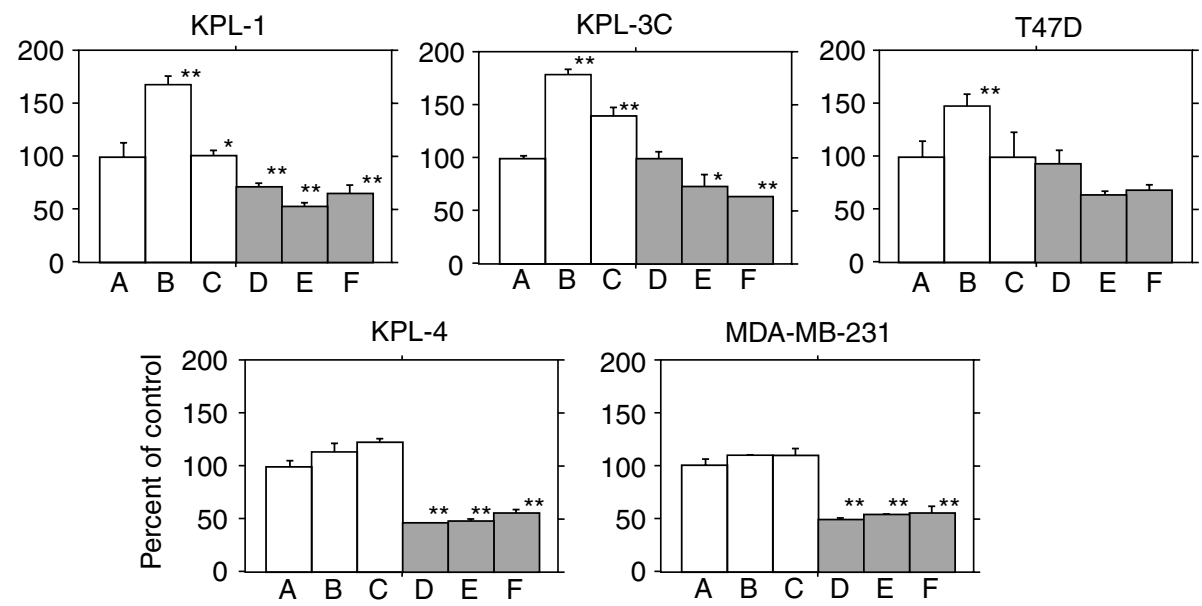

Figure 3 Effect of E2, fulvestrant and gefitinib on the cell growth of five human breast cancer cell lines tested. Semiconfluent cells were cultured for 2 days in the oestrogen-deprived medium with vehicle (control, A), I nM E2 (B), I nM E2 plus I 00 nM fulvestrant (C), I nM E2 plus I0 $\mu$ M gefitinib (D), I nM E2 plus $100 \mathrm{nM}$ fulvestrant and $10 \mu \mathrm{M}$ gefitinib (E) or $10 \mu \mathrm{M}$ gefitinib alone (F). After cell dispersion, the cell numbers were measured with a Coulter counter. Triplicate wells were treated in each experiment. Values represent means \pm s.e. $* P<0.05$ and $* * P<0.0$ I in comparison with control.

To clarify the additive antitumour effect of gefitinib and fulvestrant, various concentrations of gefitinib and fulvestrant were administered to KPL-3C cells under E2-supplemented conditions. Either gefitinib or fulvestrant dose dependently inhibited the growth of KPL-3C cells (Figure 4A). Gefitinib (0.1 $20 \mu \mathrm{M})$ additively increased the antitumour activity of fulvestrant $(1-200 \mathrm{nM})$ in KPL-3C cells (Figure 4B).

\section{Effects of E2, fulvestrant and gefitinib on cell cycle progression}

In KPL-3C cells, $1 \mathrm{~nm}$ E2 significantly increased an S-phase fraction and decreased a G0/G1-phase fraction, that is, stimulated a G1-S transition. Both $100 \mathrm{nM}$ fulvestrant and $10 \mu \mathrm{M}$ gefitinib significantly inhibited the G1-S transition stimulated by E2, that is, lead to the G1-S blockade. The simultaneous addition of fulvestrant and gefitinib additively reduced the upregulation of a $\mathrm{G} 1-\mathrm{S}$ transition by E2. A slight increase in a sub-G1 fraction was observed in the cells treated with gefitinib alone. Gefitinib alone significantly increased the sub-G1 fraction in MDA-MB-231 cells (Table 2).

\section{Effect of gefitinib on apoptosis}

To clarify whether the sub-G1 fraction detected by the cell cycle analysis represented apoptosis, KPL-3C cells treated with E2, fulvestrant and gefitinib and MDA-MB-231 cells treated gefitinib alone were subjected to the apoptosis assay. As shown in Figure 5, a significant increase in the apoptotic fraction was observed in the treated cells in comparison with the respective control cells.

\section{Effects of E2, fulvestrant and gefitinib on expression levels of p21, p27, Bcl-2 and Bax}

E2 decreased p21 expression in KPL-3C cells (a $21 \pm 15 \%$ reduction in comparison with control, $n=2)$. Both fulvestrant and gefitinib significantly increased the p21 expression decreased by E2 $(30 \pm 8$ and $45 \pm 5 \%$ increases, respectively). The simultaneous addition of the two agents additively increased the p21 expression decreased by E2 (a $88 \pm 22 \%$ increase). Gefitinib alone also increased p 21 expression in comparison with control (a $66 \pm 28 \%$ increase) (Figure 6A). In contrast, neither E2 nor fulvestrant changed p21
A

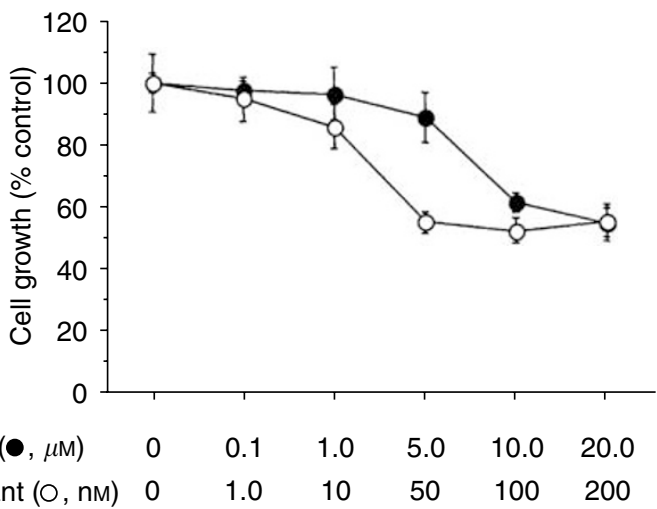

B

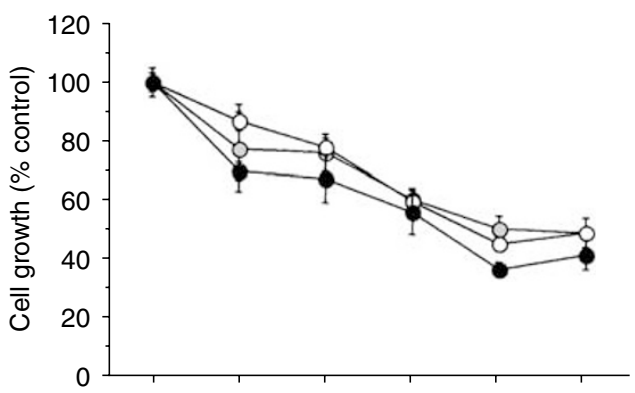

Fulvestrant (nm)

\begin{tabular}{ccccccc}
$\circ$ & 0 & 50 & 50 & 50 & 50 & 50 \\
\hline 0 & 0 & 100 & 100 & 100 & 100 & 100 \\
\hline- & 0 & 200 & 200 & 200 & 200 & 200 \\
\hline & 0 & 0 & 1 & 5 & 10 & 20
\end{tabular}

Figure 4 Effect of E2, fulvestrant and gefitinib on the cell growth of ERpositive KPL-3C cells. Semiconfluent cells were cultured for 2 days in the oestrogen-deprived medium with I nM E2 plus the indicated concentrations of gefitinib or $\mathrm{ICl}$ |82,780 (A). To clarify additive antitumour effect of gefitinib and $\mathrm{ICI}$ 182,780, semiconfluent cells were cultured for 2 days in the oestrogen-deprived medium with I nM E2, 50, I 00 or $200 \mathrm{nM} \mathrm{ICl} \mathrm{|82,780}$ plus the indicated concentrations of gefitinib (B). After cell dispersion, the cell numbers were measured with a Coulter counter. Triplicate wells were treated in each experiment. Values represent means \pm s.e. 
Table 2 Effects of E2, fulvestrant and gefitinib on cell cycle progression in KPL-3C and MDA-MB-23I cells

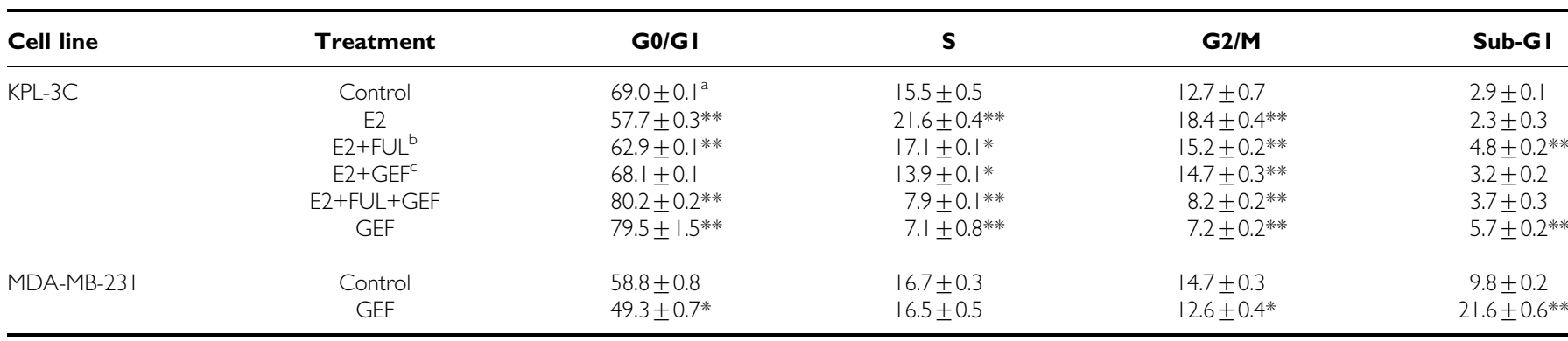

aPercentages (mean \pm s.e.). ${ }^{b}$ Fulvestrant. ${ }^{c}$ Gefitinib. $* P<0.05$; $* * P<0.01$ in comparison with the respective control.

Control

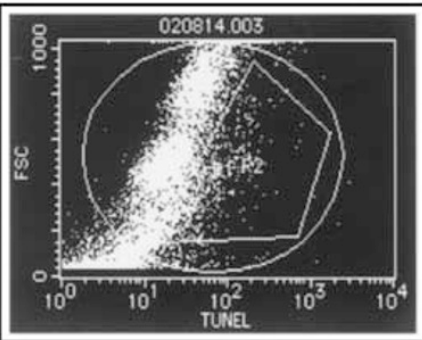

Apoptotic fraction: $11.7 \%$

Control

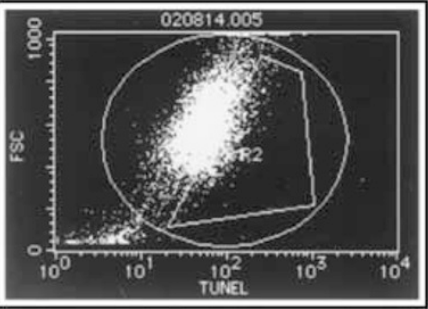

Apoptotic fraction: $11.4 \%$
E2+gefitinib+fullvestrant

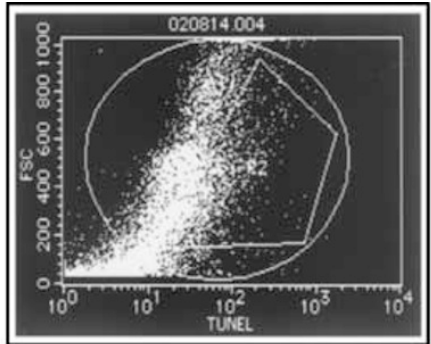

Apoptotic fraction: $29.0 \%$

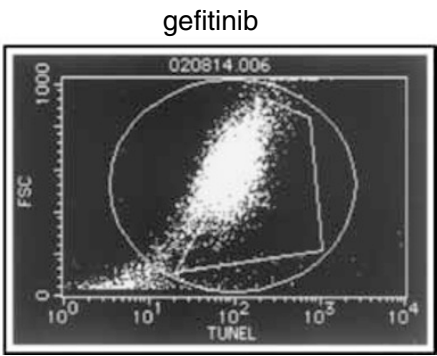

Apoptotic fraction: $40.0 \%$

Figure 5 Analyses of apoptosis in KPL-3C and MDA-MB-23I cells treated with E2, fulvestrant and/or gefitinib. Semi-confluent cells were cultured for 4 days in the oestrogen-deprived medium with vehicle (control), I nM E2 plus $100 \mathrm{nM}$ fulvestrant and $10 \mu \mathrm{M}$ gefitinib or $10 \mu \mathrm{M}$ gefitinib alone. The percentages of apoptotic cells were measured with a flow cytometry using an in situ cell death detection kit. Note the increase in apoptotic cells by the addition of fulvestrant and gefitinib to $\mathrm{E} 2$ in $\mathrm{KPL}-3 \mathrm{C}$ cells and in MDA-MB-23I cells treated with gefitinib alone.

expression in MDA-MB-231 cells. Gefitinib alone significantly increased p21 expression in comparison with control (a $222 \pm 4 \%$ increase) (Figure 6B). No significant change in p27 expression was observed in either cell lines treated with these three agents (Figure $6 \mathrm{~A}$ and $\mathrm{B})$.

E2 significantly increased Bcl-2 expression in KPL-3C cells (a $196 \pm 120 \%$ increase). Either fulvestrant or gefitinib decreased the Bcl-2 expression increased by E2 (105 \pm 33 and $130 \pm 14 \%$ reductions, respectively). The simultaneous addition of the two agents additively decreased the Bcl-2 expression increased by E2 (a $169 \pm 25 \%$ reduction). Gefitinib alone did not significantly decrease Bcl-2 expression (Figure 7A). In contrast, neither E2 nor fulvestrant changed $\mathrm{Bcl}-2$ expression in MDA-MB-231 cells. Gefitinib alone significantly decreased Bcl-2 expression in comparison with control (a $46 \pm 33 \%$ reduction) (Figure $7 \mathrm{~B}$ ). No significant change in BAX expression levels was observed in either cell lines treated with these three agents (Figure 7A and B).

The relative expression levels of p 21 and $\mathrm{Bcl}-2$, which were normalised to actin or $\alpha$-tubulin bands, and quantified by comparing with those of control cells, are shown in Figure $8 \mathrm{~A}$ and $\mathrm{B}$.

\section{DISCUSSION}

The mechanism of action of the EGFR-TKI gefitinib has been extensively studied in the last few years. It has been known that gefitinib selectively inhibits ATP binding to the ATP site of EGFR/ HER 1 and this leads to inhibition of ligand-dependent EGFR autophosphorylation and of transactivation of downstream signalling pathways, such as Ras/Raf/ERK/MAPK and PI3K/AKT cascades. Blockade of the EGFR signalling pathways results in not only retardation of cell cycle progression but also induction of apoptosis in EGFR-expressing tumour cells. It has been suggested that the cell cycle retardation is mediated by an increase in the expression level of a CDKI p27 (Moasser et al, 2001; Albanell et al, 2002; Janne et al, 2002), and that the induction of apoptosis is mediated by a decrease in the expression level of an antiapoptotic 
A

\begin{tabular}{|c|c|c|c|c|c|c|}
\hline E2 & - & + & + & + & + & - \\
\hline Fulvestrant & - & - & + & - & + & - \\
\hline Gefitinib & - & - & - & + & + & + \\
\hline
\end{tabular}

p21

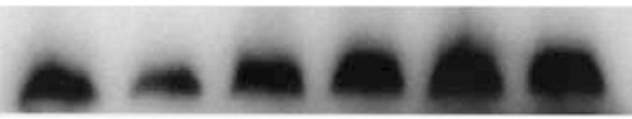

Actin

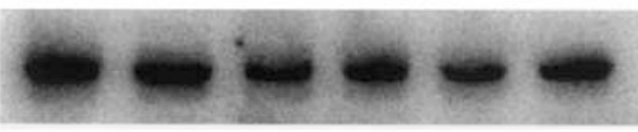

p27

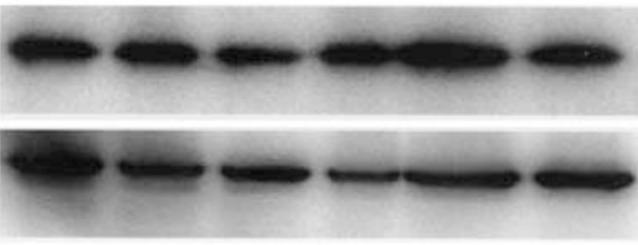

B

\begin{tabular}{|c|c|c|c|c|c|c|}
\hline E2 & - & + & + & + & + & - \\
\hline Fulvestrant & - & - & + & - & + & - \\
\hline Gefitinib & - & - & - & + & + & + \\
\hline
\end{tabular}

p21

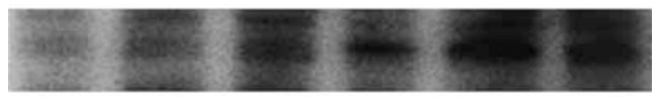

$\alpha$-Tubulin

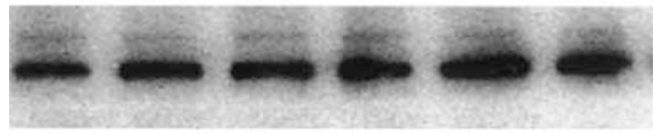

p27

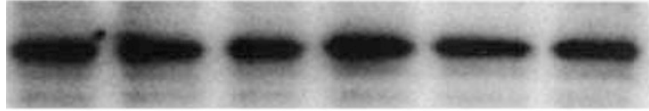

Actin

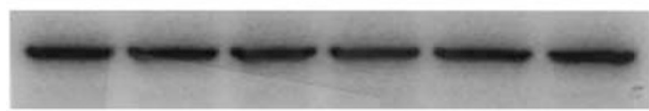

Figure 6 Western blot analysis on expression levels of CDKIs p2I and p27 in KPL-3C (A) and MDA-MB-23I (B) cells. Semi-confluent cells were cultured for 2 days in the oestrogen-deprived medium with vehicle (control), I nM E2, I nM E2 plus $100 \mathrm{nM}$ fulvestrant, I nM E2 plus $10 \mu \mathrm{M}$ gefitinib, I nM E2 plus $100 \mathrm{nM}$ fulvestrant and $10 \mu \mathrm{M}$ gefitinib or $10 \mu \mathrm{M}$ gefitinib alone. The harvested cells were lysed, and the lysate was subjected to electrophoresis on polyacrylamide gel. The protein was transferred to nitrocellulose membranes and immunoblotted with appropriate primary antibodies. For detection, the blots were incubated with the appropriate secondary antibodies conjugated with horseradish peroxidase, and developed using ECL Plus Western Blotting Detection Reagents. Actin or $\alpha$-tubulin was used as the internal control.

protein Bcl-2 (Bianco et al, 2002; Ciardiello et al, 2002; Nicholson et $a l, 2002)$ or by activation of a proapoptotic protein BAD (Gilmore et al, 2002). Very recently, it has been reported that the EGFR-TKI gefitinib increases both p27 and p21 proteins associated with CDK2-cyclin-E and CDK2-cyclin-A complexes in HER1overexpressing head and neck squamous carcinoma cells (Di Gennaro et al, 2003). In addition, gefitinib has been suggested to decrease the expression levels of proangiogenic factors, such as vascular endothelial growth factor and basic fibroblast growth factor in tumour cells, to inhibit migration and tube formation of endothelial cells and to reduce the invasive potential of tumour
A

\begin{tabular}{|c|c|c|c|c|c|c|}
\hline E2 & - & + & + & + & + & - \\
\hline Fulvestrant & - & - & + & - & + & - \\
\hline Gefitinib & - & - & - & + & + & + \\
\hline
\end{tabular}

Bax

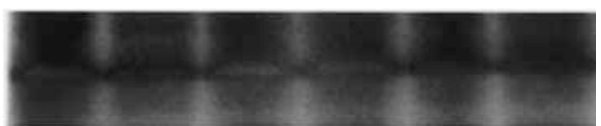

$\alpha$-Tubulin

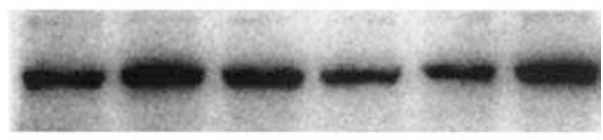

$\mathrm{Bcl}-2$

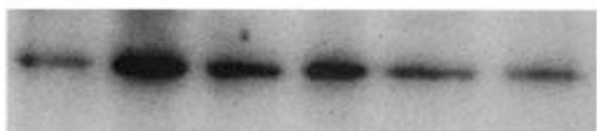

Actin

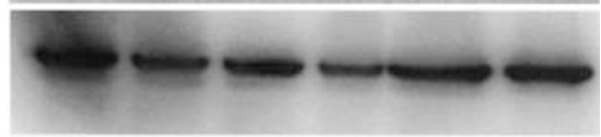

B

\begin{tabular}{|c|c|c|c|c|c|c|}
\hline E2 & - & + & + & + & + & - \\
\hline Fulvestrant & - & - & + & - & + & - \\
\hline Gefitinib & - & - & - & + & + & + \\
\hline
\end{tabular}

Bax

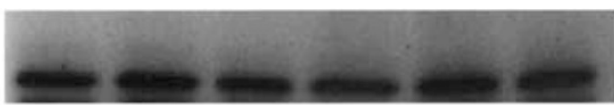

Actin

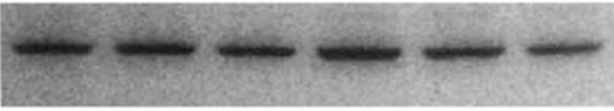

$\mathrm{Bcl}-2$

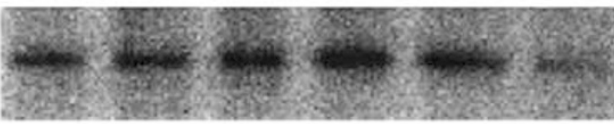

Actin

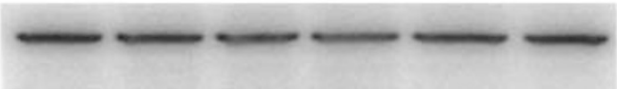

Figure 7 Western blot analysis on the expression levels of a proapoptotic protein BAX and an anti-apoptotic protein Bcl-2 in KPL-3C (A) and MDA-MB-23I (B) cells. Semi-confluent cells were cultured for 2 days in the oestrogen-deprived medium with vehicle (control), I nM E2, I nM E2 plus I $00 \mathrm{~nm}$ fulvestrant, I nM E2 plus $10 \mu \mathrm{M}$ gefitinib, I nM E2 plus I00 nM fulvestrant and $10 \mu \mathrm{M}$ gefitinib or $10 \mu \mathrm{M}$ gefitinib alone. The harvested cells were lysed, and the lysate was subjected to electrophoresis on polyacrylamide gel. The protein was transferred to nitrocellulose membranes and immunoblotted with appropriate primary antibodies. For detection, the blots were incubated with the appropriate secondary antibodies conjugated with horseradish peroxidase, and developed using ECL Plus Western Blotting Detection Reagents. Actin or $\alpha$-tubulin was used as the internal control.

cells (Ciardiello et al, 2001; Bianco et al, 2002; Fujimura et al, 2002; Hirata et al, 2002). Synergy of these mechanisms of action of gefitinib may provide a drastic antitumour effect in vivo.

It has been recognised that activation of oncogenic tyrosine kinase pathways, such as EGFR signaling pathway, leads to acquisition of resistance to radiotherapy and cytotoxic chemotherapy (Skorski, 2002). Actually, several experimental studies have suggested that the combined treatment with gefitinib and ionising 
A

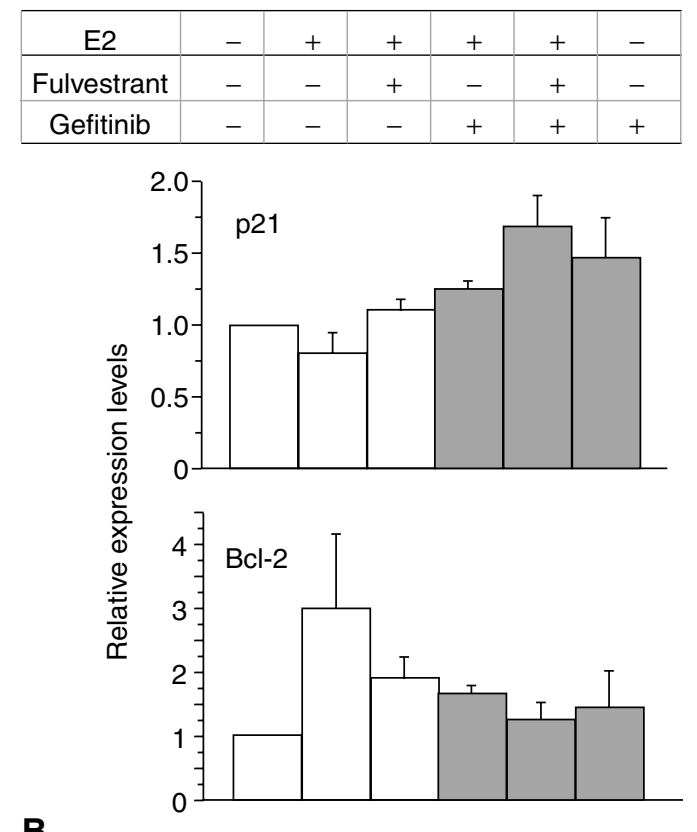

B

\begin{tabular}{|c|c|c|c|c|c|c|}
\hline E2 & - & + & + & + & + & - \\
\hline Fulvestrant & - & - & + & - & + & - \\
\hline Gefitinib & - & - & - & + & + & + \\
\hline
\end{tabular}

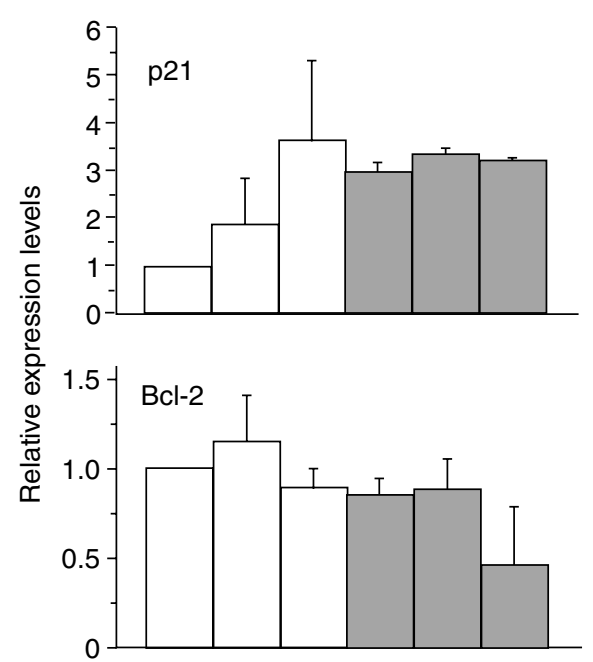

Figure 8 The relative expression levels of $\mathrm{p} 2 \mathrm{I}$ and $\mathrm{Bcl}-2$ in $\mathrm{KPL}-3 \mathrm{C}(\mathbf{A})$ and MDA-MB-23I (B) cells. Western blot bands were normalized to actin or $\alpha$-tubulin bands and quantified by comparing with those of control cells. Data are shown as the means of two separate experiments; bars, s.e.

radiation or cytotoxic agents, such as taxanes and cisplatin, synergistically inhibit the growth of tumour cells both in vitro and in vivo (Ciardiello et al, 2000; Sirotnak et al, 2000; Ciardiello et al, 2001; Bianco et al, 2002; Ciardiello et al, 2002; Huang et al, 2002; Magne et al, 2002; Williams et al, 2002). However, no synergistic or additive activity has been reported with gefitinib and a cytotoxic agent in phase III clinical trials (Giaccone et al, 2002; Johnson et al, 2002). Furthermore, it has been suggested that high expression of EGFR or HER2 causes the development of acquired endocrine resistance in endocrine-responsive breast cancer (Benz et al, 1993; Houston et al, 1999). Therefore, it might be possible that gefitinib will enhance the antitumour effect of endocrine agents.
In the present study, gefitinib additively increased the antitumour effect of the ER antagonist fulvestrant in ER-positive human breast cancer cells lines tested (Figures 3 and 4B). Cell cycle and apoptosis analyses revealed that gefitinib and fulvestrant additively induced a G1-S blockade and apoptosis in these cells (Table 2 and Figure 5). In addition, Western blot analysis showed that both agents additively upregulated the expression level of a CDKI p21 decreased by E2 and additively downregulated the expression level of an antiapoptotic protein Bcl-2 increased by E2 (Figures 6-8). These findings suggest that the upregulation of $\mathrm{p} 21$ expression by these agents may cause the retardation of $\mathrm{Gl}-\mathrm{S}$ transition, and that the downregulation of Bcl-2 expression may cause the induction of apoptosis. Unexpectedly, expression levels of another CDKI p27 did not change during treatment with gefitinib and fulvestrant (Figure 6). To our knowledge, this is the first report suggesting that gefitinib upregulates a CDKI p21 expression decreased by E2 and this may induce, at least in part, the G1-S blockade. In addition, this is also the first report suggesting that gefitinib downregulates the intrinsic Bcl-2 expression increased by E2 and this may cause, at least in part, the induction of apoptosis. However, it is hard to clarify whether these additive effects, including antitumour activity, induction of G1-S blockade, induction of p21 expression and decrease in Bcl-2 expression, produced by gefitinib and fulvestrant in ER-positive breast cancer cells are mediated by the interaction of these drugs or by the summation of two independent actions.

Gefitinib induced neither a significant G1-S blockade nor reduction in S-phase fraction in MDA-MB-231 cells. Otherwise, a significant increase in the p21 expression level was observed (Figures $6 \mathrm{~B}$ and $8 \mathrm{~B}$ ). On the other hand, a significant downregulation of $\mathrm{Bcl}-2$ and increase in apoptosis was observed at the same time (Table 2 and Figures 7B and $8 \mathrm{~B}$ ). It might be possible that a G1-S blockade and reduction in S-phase fraction induced by gefitinib was drowned by the induction of a massive apoptosis by gefitinib in the cell cycle analysis or a G1 -S blockade appeared some time before the induction of apoptosis. Further analyses, such as time course studies of expression levels of CDKIs and apoptosis-modulating proteins are needed to understand in greater detail the mechanism of action of gefitinib.

Clinically, combined treatments with endocrine therapy and an inhibitor of growth factor signalling pathways are thought to be promising. Rationales of this hypothesis are follows: (1) clinical studies have suggested that ER-positive breast cancers with a high expression level of EGFR or HER2 are frequently resistant to endocrine therapy and have a shorter survival time (Sainsbury et al, 1987; Nicholson et al, 1989; van Agthoven et al, 1992; Newby et al, 1995; Dowsett et al, 2001), (2) artificially increasing expression of EGFR or HER2 to high levels in ER-positive breast cancer cells leads to an antioestrogen-resistant phenotype (Benz et al, 1993; Houston et al, 1999), (3) a prolonged exposure of an antioestrogen to ERpositive breast cancer cells sometimes results in upregulation of EGFR or HER2 expression and an antioestrogen-resistant phenotype (Long et al, 1992; McClelland et al, 2001; Nicholson et al, 2002), (4) we and others have suggested that an anti-HER2 monoclonal antibody or inhibitor of HER2 signalling pathway enhances an antitumour effect of antioestrogens in ER-positive breast cancer cells with a moderate or high level of HER2 expression (Witters et al, 1997; Kunisue et al, 2000; Kurokawa et al, 2000). Actually, combination therapy with trastuzumab and an endocrine agent, the aromatase inhibitor anastrozole, has been tested in a clinical trial (Winer and Burstein, 2001). Interestingly, it has been reported that a combined treatment with gefitinib and trastuzumab cooperatively inhibits the growth of breast cancer cells (Normanno et al, 2002). It might be an attractive approach to use this combination for the treatment of antioestrogen-resistant breast cancer.

In conclusion, the present study has suggested that simultaneous administration of the EGFR-TKI gefitinib and the ER antagonist fulvestrant may be more efficacious than either agent alone for the 
treatment of patients with ER-positive breast cancer, which express HER1 at various levels. In addition, the additive antitumour effect of these agents may be mediated by the additive G1-S blockade mediated by upregulation of $\mathrm{p} 21$ and by the additive induction of apoptosis mediated by downregulation of Bcl-2. These findings should be clarified in preclinical in vivo studies and in prospective randomised clinical trials in the near future.

\section{ACKNOWLEDGEMENTS}

This work was supported by grants from the Ministry of Education, Culture, Sports, Science and Technology, Japan (No. 14571166) and from the Research Project Grants of Kawasaki Medical School (No. 14-501). 'Iressa' and 'Faslodex' are trademarks of the AstraZeneca group of companies.

\section{REFERENCES}

Albanell J, Rojo F, Averbuch S, Feyereislova A, Mascaro JM, Herbst R, LoRusso P, Rischin D, Sauleda S, Gee J, Nicholson RI, Baselga J (2002) Pharmacodynamic studies of the epidermal growth factor receptor inhibitor ZD1839 in skin from cancer patients: histopathologic and molecular consequences of receptor inhibition. J Clin Oncol 20: 110-124

Arteaga CL (2002) Overview of epidermal growth factor receptor biology and its role as a therapeutic target in human neoplasia. Semin Oncol 5(Suppl 14): 3-9

Baselga J, Averbuch SD (2000) ZD1839 ('Iressa') as an anticancer agent. Drugs 60(Suppl 1): 33-40

Baselga J, Rischin D, Ranson M, Calvert H, Raymond E, Kieback DG, Kaye SB, Gianni L, Harris A, Bjork T, Averbuch SD, Feyereislova A, Swaisland H, Rojo F, Albanell J (2002) Phase I safety, pharmacokinetic, and pharmacodynamic trial of ZD1839, a selective oral epidermal growth factor receptor tyrosine kinase inhibitor, in patients with five selected solid tumor types. J Clin Oncol 20: 4292-4302

Benz CC, Scott GK, Sarup JC, Johnson RM, Tripathy D, Coronado E, Shepard HM, Osborne CK (1993) Estrogen-dependent, tamoxifenresistant tumorigenic growth of MCF-7 cells transfected with HER2/ neu. Breast Cancer Res Treat 24: 85-95

Bianco C, Tortora G, Bianco R, Caputo R, Veneziani BM, Caputo R, Damiano V, Troiani T, Fontanini G, Raben D, Pepe S, Bianco AR, Ciardiello F (2002) Enhancement of antitumor activity of ionizing radiation by combined treatment with the selective epidermal growth factor receptor-tyrosine kinase inhibitor ZD1839 (Iressa). Clin Cancer Res 8: $3250-3258$

Ciardiello F, Caputo R, Bianco R, Damiano V, Fontanini G, Cuccato S, De Placido S, Bianco AR, Tortora G (2001) Inhibition of growth factor production and angiogenesis in human cancer cells by ZD1839 (Iressa), a selective epidermal growth factor receptor tyrosine kinase inhibitor. Clin Cancer Res 7: 1459-1465

Ciardiello F, Caputo R, Bianco R, Damiano V, Pomatico G, De Placido S, Bianco AR, Tortora G (2000) Antitumor effect and potentiation of cytotoxic drugs activity in human cancer cells by ZD-1839 (Iressa), an epidermal growth factor receptor-selective tyrosine kinase inhibitor. Clin Cancer Res 6: $2053-5063$

Ciardiello F, Caputo R, Borriello G, Del Bufalo D, Biroccio A, Zupi G, Bianco AR, Tortora G (2002) ZD1839 (IRESSA), an EGFR-selective tyrosine kinase inhibitor, enhances taxane activity in bcl-2 overexpressing, multidrug-resistant MCF-7 ADR human breast cancer cells. Int $J$ Cancer 98: 463-469

Di Gennaro E, Barbarino M, Bruzzese F, De Lorenzo S, Caraglia M, Abbruzzese A, Avallone A, Comella P, Caponigro F, Pepe S, Budillon A (2003) Critical role of both p27KIP1 and p21CIP/WAF1 in the antiproliferative effect of ZD1839 ('Iressa'), an epidermal growth factor receptor tyrosine kinase inhibitor, in head and neck squamous carcinoma cells. J Cell Physiol 195: 139-150

Dowsett M, Harper-Wynne C, Boeddinghaus I, Salter J, Hills M, Dixon M, Ebbs S, Gui G, Sacks N, Smith I (2001) HER-2 amplification impedes the antiproliferative effects of hormone therapy in estrogen receptor-positive primary breast cancer. Cancer Res 61: $8452-8458$

Fujimura M, Hidaka T, Saito S (2002) Selective inhibition of the epidermal growth factor receptor by ZD1839 decreases the growth and invasion of ovarian clear cell adenocarcinoma cells. Clin Cancer Res 8: $2448-2454$

Giaccone G, Johnson DH, Mangegold C, Scagliotti GV, Rosell R, Wolf M, Rennie P, Ochs J, Averbuch S, Fandi AA (2002) A phase III clinical trial of ZD1839 ('Iressa') in combination with gemcitabine and cisplatin in chemotherapy-naïve patients with advanced non-small-cell lung cancer (INTACT 1). Ann Oncol 13(Suppl 5): 2

Gilmore AP, Valentijn AJ, Wang P, Ranger AM, Bundred N, O'Hare MJ, Wakeling A, Korsmeyer SJ, Streuli CH (2002) Activation of BAD by therapeutic inhibition of epidermal growth factor receptor and transactivation by insulin-like growth factor receptor. J Biol Chem 277: $27643-27650$

Herbst RS, Maddox AM, Rothenberg ML, Small EJ, Rubin EH, Baselga J, Rojo F, Hong WK, Swaisland H, Averbuch SD, Ochs J, LoRusso PM (2002) Selective oral epidermal growth factor receptor tyrosine kinase inhibitor ZD1839 is generally well-tolerated and has activity in nonsmall-cell lung cancer and other solid tumors: results of a phase I trial. J Clin Oncol 20: $3815-3825$

Hirata A, Ogawa S, Kometani T, Kuwano T, Naito S, Kuwano M, Ono M (2002) ZD1839 (Iressa) induces antiangiogenic effects through inhibition of epidermal growth factor receptor tyrosine kinase. Cancer Res 62: $2554-2560$

Houston SJ, Plunkett TA, Barnes DM, Smith P, Rubens RD, Miles DW (1999) Overexpression of c-erbB2 is an independent marker of resistance to endocrine therapy in advanced breast cancer. $\mathrm{Br} J$ Cancer 79: $1220-1226$

Huang SM, Li J, Armstrong EA, Harari PM (2002) Modulation of radiation response and tumor-induced angiogenesis after epidermal growth factor receptor inhibition by ZD1839 (Iressa). Cancer Res 62: 4300-4306

Janne PA, Taffaro ML, Salgia R, Johnson BE (2002) Inhibition of epidermal growth factor receptor signaling in malignant pleural mesothelioma. Cancer Res 62: $5242-5247$

Johnson DH, Herbst R, Giaccone G, Schiller J, Natale RB, Miller V, Wolf M, Helton A, Averbuch S, Grous J (2002) ZD1839 ('iressa') in combination with paclitaxel \& carboplatin in chemotherapy-naïve patients with advanced non-small-cell lung cancer (NSCLC): results from a phase III clinical trial (INTACT 2). Ann Oncol 13(Suppl 5): 127

Kunisue H, Kurebayashi J, Otsuki T, Tang CK, Kurosumi M, Yamamoto S, Tanaka K, Doihara H, Shimizu N, Sonoo H (2000) Anti-HER2 antibody enhances the growth inhibitory effect of anti-oestrogen on breast cancer cells expressing both oestrogen receptors and HER2. Br J Cancer 82: $46-51$

Kurebayashi J, Kunisue H, Yamamoto S, Kurosumi M, Otsuki T, Sonoo H (2000a) Paradoxical hormone responses of KPL-1 breast cancer cells in vivo: a significant role of angiogenesis in tumor growth. Oncology 59: $158-165$

Kurebayashi J, Kurosumi M, Sonoo H (1995) A new human breast cancer cell line, KPL-1 secretes tumour-associated antigens and grows rapidly in female athymic nude mice. Br J Cancer 71: 845-853

Kurebayashi J, Kurosumi M, Sonoo H (1996) A new human breast cancer cell line, KPL-3C, secretes parathyroid hormone-related protein and produces tumours associated with microcalcifications in nude mice. $\mathrm{Br}$ Cancer 74: 200-207

Kurebayashi J, Otsuki T, Kunisue H, Tanaka K, Yamamoto S, Sonoo H (2000b) Expression levels of estrogen receptor-alpha, estrogen receptorbeta, coactivators, and corepressors in breast cancer. Clin Cancer Res 6: $512-518$

Kurebayashi J, Otsuki T, Tang CK, Kurosumi M, Yamamoto S, Tanaka K, Mochizuki M, Nakamura H, Sonoo H (1999) Isolation and characterization of a new human breast cancer cell line, KPL-4, expressing the Erb B family receptors and interleukin-6. Br J Cancer 79: 707-717

Kurokawa H, Lenferink AE, Simpson JF, Pisacane PI, Sliwkowski MX, Forbes JT, Arteaga CL (2000) Inhibition of HER2/neu (erbB-2) and mitogen-activated protein kinases enhances tamoxifen action against HER2-overexpressing, tamoxifen-resistant breast cancer cells. Cancer Res 60: $5887-5894$

Long B, McKibben BM, Lynch M, van den Berg HW (1992) Changes in epidermal growth factor receptor expression and response to ligand associated with acquired tamoxifen resistance or oestrogen independence in the ZR-75-1 human breast cancer cell line. Br J Cancer 65: $865-869$ 
Magne N, Fischel JL, Dubreuil A, Formento P, Marcie S, Lagrange JL, Milano G (2002) Sequence-dependent effects of ZD1839 ('Iressa') in combination with cytotoxic treatment in human head and neck cancer. Br J Cancer 86: 819-827

McClelland RA, Barrow D, Madden TA, Dutkowski CM, Pamment J, Knowlden JM, Gee JM, Nicholson RI (2001) Enhanced epidermal growth factor receptor signaling in MCF7 breast cancer cells after long-term culture in the presence of the pure antiestrogen ICI 182,780 (Faslodex). Endocrinology 142: 2776-2788

Moasser MM, Basso A, Averbuch SD, Rosen N (2001) The tyrosine kinase inhibitor ZD1839 ('Iressa') inhibits HER2-driven signaling and suppresses the growth of HER2-overexpressing tumor cells. Cancer Res 61: $7184-7188$

Moulder SL, Yakes FM, Muthuswamy SK, Bianco R, Simpson JF, Arteaga CL (2001) Epidermal growth factor receptor (HER1) tyrosine kinase inhibitor ZD1839 (Iressa) inhibits HER2/neu (erbB2)-overexpressing breast cancer cells in vitro and in vivo. Cancer Res 61: 8887-8895

Newby JC, A'Hern RP, Leek RD, Smith IE, Harris AL, Dowsett M (1995) Immunohistochemical assay for epidermal growth factor receptor on paraffin-embedded sections: validation against ligand-binding assay and clinical relevance in breast cancer. $\mathrm{Br}$ J Cancer 71: 1237-1242

Nicholson RI, Hutcheson IR, Harper ME, Knowlden JM, Barrow D, McClelland RA, Jones HE, Wakeling AE, Gee JM (2002) Modulation of epidermal growth factor receptor in endocrine-resistant, estrogenreceptor-positive breast cancer. Ann N Y Acad Sci 963: 104-115

Nicholson S, Sainsbury JR, Halcrow P, Chambers P, Farndon JR, Harris AL (1989) Expression of epidermal growth factor receptors associated with lack of response to endocrine therapy in recurrent breast cancer. Lancet 1(8631): $182-185$

Normanno N, Campiglio M, De LA, Somenzi G, Maiello M, Ciardiello F Gianni L, Salomon DS, Menard S (2002) Cooperative inhibitory effect of ZD1839 (Iressa) in combination with trastuzumab (Herceptin) on human breast cancer cell growth. Ann Oncol 13: 65-72
Ranson M, Hammond LA, Ferry D, Kris M, Tullo A, Murray PI, Miller V, Averbuch S, Ochs J, Morris C, Feyereislova A, Swaisland H, Rowinsky EK (2002) ZD1839, a selective oral epidermal growth factor receptor-tyrosine kinase inhibitor, is well tolerated and active in patients with solid, malignant tumors: results of a phase I trial. J Clin Oncol 20: $2240-2250$

Sainsbury JR, Farndon JR, Needham GK, Malcolm AJ, Harris AL (1987) Epidermal-growth-factor receptor status as predictor of early recurrence of and death from breast cancer. Lancet 1(8547): 1398-1402

Sirotnak FM, Zakowski MF, Miller VA, Scher HI, Kris MG (2000) Efficacy of cytotoxic agents against human tumor xenografts is markedly enhanced by coadministration of ZD1839 (Iressa), an inhibitor of EGFR tyrosine kinase. Clin Cancer Res 6: $4885-4892$

Skorski T (2002) Oncogenic tyrosine kinases and the DNA-damage response. Nat Rev Cancer 2: 351-360

van Agthoven T, van Agthoven TL, Portengen H, Foekens JA, Dorssers LC (1992) Ectopic expression of epidermal growth factor receptors induces hormone independence in ZR-75-1 human breast cancer cells. Cancer Res 52: $5082-5088$

Wakeling AE, Nicholson RI, Gee JM (2001) Prospects for combining hormonal and nonhormonal growth factor inhibition. Clin Cancer Res 7(12 Suppl): $4350 \mathrm{~s}-4355 \mathrm{~s}$

Williams KJ, Telfer BA, Stratford IJ, Wedge SR (2002) ZD1839 ('Iressa'), a specific oral epidermal growth factor receptor-tyrosine kinase inhibitor, potentiates radiotherapy in a human colorectal cancer xenograft model. Br J Cancer 86: $1157-1161$

Winer EP, Burstein HJ (2001) New combinations with Herceptin in metastatic breast cancer. Oncology 61(Suppl 2): 50-57

Witters LM, Kumar R, Chinchilli VM, Lipton A (1997) Enhanced antiproliferative activity of the combination of tamoxifen plus HER-2-neu antibody. Breast Cancer Res Treat 42: $1-5$

Yarden Y, Sliwkowski MX (2001) Untangling the ErbB signaling network. Nat Rev Mol Cell Biol 2: 127-137 